\title{
Correlation between Nicotinamide Phosphoribosyl Transferase(NAMPT) level andclinicopathological criteria in colorectal cancer patients
}

\author{
Madeha M. Zakhary ${ }^{1}$, Ashraf M. Albadry ${ }^{2}$,SamerA.Alsawy ${ }^{3}$,AliaKh.Mahmoud ${ }^{3}$ \\ Departments of Biochemistry ${ }^{1,3} \&$ General Surgery ${ }^{2}$ Faculty of Medicine \\ ,Assiut ${ }^{1}$ andSohaguniversity ${ }^{2,3}$.
}

\begin{abstract}
Background:Colorectal cancer (CRC) is one of the most common cancers worldwide, with the highest incidence rates in western countriesThe 5-year survival rate for a patient diagnosed with stage I or II colorectal cancer, is up to 90\%. However, the 5year survival rate for patients diagnosed with stage IV disease, once the cancer has metastasized to other organs, is only $12 \%$.

Aim of the work :is todetect levels of Visfatin,Nitric oxide,Lipid peroxide and Superoxide dismutase in serum of patients with colorectal cancer and compare results with patients with benign colorectal tumor and with control group and detect the relation of each of them to the clinic-pathological criteria in colorectal cancer.

Patients and methods: This study was performed at Sohag University Hospital from December 2015 to June 2016, eighty-five persons were enrolled in the study and divided into three groups. 60 patients with colorectal cancer, 10 patients with begin colorectal tumors all of them were selected from SohagCancer Institute and Sohag University Hospital and 15 healthy persons of matched age and sex without evidence of any cancer (controls). All were matched for age and sex, for each participantcomplete medical history, physical examination, and routine investigations were done.Nicotinamidephosphoribosyltransferase (NAMPT) was measured by Eliza kitsNitric oxide and Superoxide dismutase (SOD) activities level were measured by colorimetry..
\end{abstract}

Results: The serum levels of visfatin"NAMPT",NO and lipid peroxidation products as "MDA"in patients with benign tumor were significantly higher than in healthy controls, in patients with colorectal cancer the levels is significantly higher than in healthy controls and patients with benign tumor ( $p$-value $<0.001$ ), and there is significant relations between levels of NAMPT and the clinicopathologicalcritiria of the cancer ,In contrast the levels of antioxidant enzyme (superoxide dismutase) where altered"decreased "in colorectal cancer group, benign lesions group comparing to healthy control group .

Conculsion:our study relieved that there is positive relation between level of visfatin and colorectal caneroccurance and cancer clinicopathological criteria . Also our study relievedColorectal carcinogenesis is associated with serious oxidative stress and confirms that gradual advancement of oxidative-antioxidative disorders is followed by progression of colorectal cancer.

Keywords:NAMPT, oxidants, antioxidant activity, Colorectal cancer . E-mail:aliakhairy88@gmail.com.Tel:01023742566.

\section{Introduction}

Colorectal cancer is the third most common cancer and the third leading cause of cancer death expected to occur in both men and women in the United States in 2014(1) and accounted for almost $10 \%$ of global cancer incidence burden in 2012(2).
Colorectal cancer is one of the most common cancers in the world, with over 1.2

million new cases diagnosed each year (3). Despite improvements in screening for early diagnosis, colorectal cancer 
remains one of the biggest cancer killers in the world and is responsible for over 600,000 deaths each year (3).

Initially, it is developed as a benign precursor lesion (adenoma), which can progress to an invasive lesion (adenocarcinoma) with the capacity to metastasize (metastatic adenocarcinoma).

The 5-year survival rate of this disease is approximately $90 \%$ for patients with localized disease and approximately $66 \%$ for patients with regional disease, as determined at diagnosis(4).

Also, known in the literature as visfatin or pre-B cell enhancing factor (PBEF) which was isolated from peripheral blood lymphocytes and described as a secreted growth factor for early B cell proliferation(5) possesses many important functions for cellular pathophysiology being an insulin-mimetic adipokine which is highly expressed and secreted by visceral adipose tissue, associated with obesity(6).

Furthermore, Nampt is the rate-limiting enzyme that converts nicotinamide into $\mathrm{NAD}^{+}$which is essential for cellular metabolism, energy production, DNA repair, and survival (7).It is well known that cancer cells have a higher basal turnover of NAD and display higher energy requirements compared with non-malignant cells. Increasing evidence demonstrated that Nampt acts as a multifunctional enzyme and is important for the metabolism and immune response as well as cancer disease development (8).

The dysregulation of NAMPT gene as well as abnormalities in circulating NAMPT levels have been implicated in the susceptibility and pathogenesis of a number of human diseases and pathologic conditions, NAMPT has been implicated in cancer as breast cancer, colorectalcancer, gastriccancer, prostaticcancer, braintumors and ovarian cancer, obesity, aging, atherosclerosis, sepsis, acute lung injury, rheumatoid arthritis(9).

Nampt was first reported to be overexpressed in colorectal cancer using suppression subtractive hybridization (10). Additionally, plasma Nampt levels in patients with advanced and early cancer were higher than in controls (11). However, the expression of Nampt in both of human colorectal adenoma and carcinoma tissues was not explored yet.Furthermore, whether Nampt expression is associated with clinicopathological characteristics in colorectal carcinoma tissue is unknown There is growing support for the concept that reactive oxygen species (ROS) which are known to be implicated in a range of diseases, may be important progenitors in carcinogenesis (12). In the last decade, growing number of reports investigating association between ROS and carcinogenesis have been published $(12,13,14)$. However, recent evidence has suggested that the generation of ROS may play important role in all phases of carcinogenesis, that is, the initiation, promotion, and progression stages (12).

DNA damage can result in either cell cycle arrest or induction of transcription, induction of signal transduction pathways, replication errors, and genomic instability, all of which are associated with colon carcinogenesis (12).

\section{Aim of the work}

The aim of the present study is to: 1-Evaluate the levels of (NAMPT) in patients with colorectal adenomas and carcinomas.

2-Detect whether NAMPT levels is correlated with clinicopathologicalcritiria in colorectal tumors.

3-Detect oxidative stress status in patients with colorectal cancer byestimatingthelevels nitric oxide and 
that of final lipid peroxidation products like (MDA) malondialdehyde.

4-Detect antioxidant status in patients with colorectal cancer be estimating level of antioxidative enzymes as superoxide dismutase (SOD).

\section{Patientes and method}

This study was performed at Sohag University Hospital from December 2015 to June 2016, The study was approved by the ethics committee of Sohag faculty of Medicine and informed consents were obtained from all individuals included in the study. All individuals were informed regarding the tests and their clinical meanings before the study.

\section{I - patients:}

Our study included;70 patients with colorectal tumors who were selected from Sohag Cancer Institute and Sohag University Hospital. They were dividedinto 2 groups according to the type of the tumor:

-GroupIpatients with malignant tumor $(\mathrm{n}=60)$.

-Group IIpatients with benign tumor $(\mathrm{n}=10)$.

The control group $(n=15)$.

Complete medical history, physical examination, and routine investigations were done for all participants:Complete blood count(CBC), Kidney function test andLiver function test. All patients were subjected to abdominal computer tomography, magnetic resonance imaging andupper and lower endoscopy when required. The colorectal cancer was classified according to TNM staging system.

In addition,they were classified according to the size of cancerinto high tumor burden $(>6 \times 6 \mathrm{~cm})$ and low tumor burden $(\leq 6 \times 6 \mathrm{~cm})$.

\section{Exclusion critiria}

Primary tumors in other organs, hereditary cancer syndrome,

previous malignancy, previous radiotherapy or chemotherapy were excluded from the study.

\section{II -Methods: -}

Random venous blood samples were withdrawn from patients and control persons,

and then centrifuged in centrifuge system for 20 minutes. Serum was removed then the samples were stored in aliquot at $-20{ }^{\circ} \mathrm{C}$ until assay.

\section{1-NAMPT (Visfatin)}

Visfatin was measured by test kits supplied by WKEA MED SUPPLIES CROP

(code NO: WH-1525) which allow determination of human Visfatin concentration in human serum using an enzyme linked immunosorbent assay (ELISA) for detection of Visfatin.

\section{2- Nitric oxide}

By Griess method we do colometric determination of nitrite supplied by Bio Diagnostic Company.

In acid, medium and in presence of nitrite the formed nitrous acid diazotisesulphanilamide and the product is coupled with $\mathrm{N}$-(1-naphthyl) ethylenediamine. the resulting azo dye has abright reddish-purple color which can be measured at $540 \mathrm{~nm}$.

\section{3-Measurement of Lipid peroxide}

\section{(MDA) levels .}

MDA levels were measured according to the manufacturers instructions (bio diagnostic; Pharmaceutical Industries, CAT. No. MD 25 29, Egypt).Thiobarbituric acid (TBA) reactswith MDA in acidic medium at temperature of $95^{\circ} \mathrm{C}$ for $30 \mathrm{~min}$ to form thiobarbituric acid reactive product the absorbance of the resultant pink product can be measured at 534 $\mathrm{nm}$.

\section{4- Measurement of SODactivities}

Superoxide dismutase activities were measured according to the manufacturer's instructions (Biodiagnostic; Pharmaceutical Industries, CAT. No. SD 25 21, Egypt). This assay relies on the ability of the enzyme to inhibit the 
SOHAG MEDICAL JOURNAL Vol. 21 No.2 July 2017 phenazinemethosulphate- mediated reduction of nitrobluetetrazolium dye .

\section{Statistical analysis:}

Data was analyzed using SPSS computer program version 22.0. Quantitative data was expressed as means \pm standard deviation, median and range. Qualitative data was expressed as number and percentage. The data were tested for normality using Kolmogrov-Smirnov test which was significant indicating the use of nonparametric tests as data wasn't normally distributed. The nonparametric Mann-Whitney test was used for comparing two quantitative variables .Kruskal-Wallis test was used for comparison between more than two quantitative variables. ChiSquare test or Fisher's Exact test were used for comparison between qualitative variables. Spearman's correlation coefficient was used for measuring correlation between the different enzymes levels.

\section{Resultes}

Table (1): Comparison of the three studied groups by socio demographic characteristics, family history and chronic illness $\left(\mathbf{N}_{\text {. }}=\mathbf{8 5}\right.$ )

\begin{tabular}{|c|c|c|c|c|}
\hline Parameter & $\begin{array}{c}\text { Malignant } \\
\text { tumor } \\
(\mathrm{N}=60)\end{array}$ & $\begin{array}{l}\text { Benign tumor } \\
\quad(\mathbf{N}=10)\end{array}$ & $\begin{array}{l}\text { Healthy } \\
\text { control } \\
(\mathrm{N}=15) \\
\end{array}$ & P-value \\
\hline $\begin{array}{l}\text { Age } \\
\text { Mean } \pm \text { S.D. } \\
\text { Median (Range) } \\
\end{array}$ & $\begin{array}{c}46.2 \pm 18.9 \\
44.5(15-82) \\
\end{array}$ & $\begin{array}{c}52.8 \pm 16.3 \\
52.5(25-75) \\
\end{array}$ & $\begin{array}{r}34.7 \pm 10.9 \\
36(20-59) \\
\end{array}$ & $0.024 *$ \\
\hline $\begin{array}{l}\text { Sex } \\
\quad \text { Males }(\%) \\
\text { Female s }(\%)\end{array}$ & $\begin{array}{l}22(56.4 \%) \\
38(82.6 \%)\end{array}$ & $\begin{array}{l}4(10.3 \%) \\
6(13.1 \%)\end{array}$ & $\begin{array}{c}13(33.3 \%) \\
2(4.3 \%)\end{array}$ & $0.002 * *$ \\
\hline $\begin{array}{l}\text { Family history } \\
\text { Negative (\%) } \\
\text { Positive (\%) } \\
\end{array}$ & $\begin{array}{l}46(83.6 \%) \\
14(93.3 \%) \\
\end{array}$ & $\begin{array}{c}9(16.4 \%) \\
1(6.7 \%) \\
\end{array}$ & -- & $0.678 * * *$ \\
\hline $\begin{array}{l}\text { Chronic illness } \\
\text { Yes }(\%) \\
\text { No }(\%)\end{array}$ & $\begin{array}{l}14(66.7 \%) \\
46(93.9 \%)\end{array}$ & $\begin{array}{c}7(33.3 \%) \\
3(6.1 \%)\end{array}$ & -- & $0.006 * * *$ \\
\hline
\end{tabular}

$* \overline{\mathbf{P}}$ - value was calculated by Kruskal Wallis test

** P- value was calculated by Chi square test

*** P-value was calculated by Fisher's Exact Test

Table (2): Comparison of Visfatin enzyme levels according to tumor burden (N. = 60)

Visfatin level is proportianalycorrelted with tumer burden

\begin{tabular}{||l||c|c|c||}
\hline \multicolumn{1}{|c|}{ Enzyme } & $\begin{array}{c}\text { High } \\
(\mathrm{N}=24)\end{array}$ & $\begin{array}{c}\text { Low } \\
(\mathrm{N}=36)\end{array}$ & P-value \\
\hline \hline $\begin{array}{l}\text { Visfatin }(\mu \mathrm{g} / \mathrm{dl}) \\
\text { Mean } \pm \text { S.D. }\end{array}$ & $15.9 \pm 2.7$ & $14.02 \pm 2.4$ & $\mathbf{0 . 0 0 6}^{*}$ \\
Median $($ Range $)$ & $16.8(11.8-19.7)$ & $14(10.9-19.1)$ & \\
\hline
\end{tabular}

P- value was calculated by Mann-Whitney test *Statistically significant. 
Table (3): Comparison of Visfatin enzyme levels according to invasiveness and metastasis $\left(N_{.}=60\right)$ Visfatin level is proportianalycorrelted with invasiveness and metastasis

\begin{tabular}{|c|c|c|c|}
\hline Enzyme & $\begin{array}{c}\text { Yes } \\
(\mathrm{N}=24) \\
\end{array}$ & $\begin{array}{c}\text { No } \\
(\mathrm{N}=36) \\
\end{array}$ & P-value \\
\hline $\begin{array}{l}\text { Visfatin }(\mu \mathrm{g} / \mathrm{dl}) \\
\text { Mean } \pm \text { S.D. } \\
\text { Median (Range) }\end{array}$ & $\begin{array}{c}17.6 \pm 1.3 \\
17.05(15.1-19.7)\end{array}$ & $\begin{array}{c}12.9 \pm 1.4 \\
12.8(10.9-15.5)\end{array}$ & $0.000 *$ \\
\hline
\end{tabular}

P- value was calculated by Mann-Whitney test *Statistically significant

Table (4): Comparison of Visfatin enzyme levels according to grade $(\mathbf{N}$. $=60)$ Visfatin level is proportianalycorrelted with tumergrade

\begin{tabular}{|c|c|c|c|c|}
\hline Enzyme & $\begin{array}{c}\text { Grade } 1 \\
(\mathrm{~N}=2)\end{array}$ & $\begin{array}{c}\text { Grade } 2 \\
(\mathrm{~N}=46)\end{array}$ & $\begin{array}{c}\text { Grade } 3 \\
(\mathrm{~N}=12)\end{array}$ & P-value \\
\hline $\begin{array}{l}\text { Visfatin }(\mu \mathrm{g} / \mathrm{dl}) \\
\text { Mean } \pm \text { S.D. } \\
\text { Median(Range) }\end{array}$ & $\begin{array}{c}14.4 \pm 0.0 \\
14.4(14.4-14.4)\end{array}$ & $\begin{array}{c}14.7 \pm 2.7 \\
14.1(11-19.7)\end{array}$ & $\begin{array}{c}15.4 \pm 3.1 \\
16.8(10.9- \\
19.1)\end{array}$ & 0.867 \\
\hline
\end{tabular}

P- value was calculated by Kruskal Wallis test.

Table (5): Comparison of Visfatin enzyme levels according to differentiation ( $N$. $=60)$ Visfatin level is proportianalycorrelted with tumerdifferentiation

\begin{tabular}{|c|c|c|c|c|}
\hline Enzyme & $\begin{array}{c}\text { Poor } \\
\text { differentiation } \\
(\mathrm{N}=16)\end{array}$ & $\begin{array}{c}\text { Moderate } \\
\text { differentiation } \\
(\mathrm{N}=38)\end{array}$ & $\begin{array}{c}\text { Well } \\
\text { differentiation } \\
(\mathrm{N}=6)\end{array}$ & $\begin{array}{c}\text { P- } \\
\text { value }\end{array}$ \\
\hline $\begin{array}{l}\text { Visfatin }(\mu \mathrm{g} / \mathrm{dl}) \\
\text { Mean } \pm \text { S.D. } \\
\text { Median(Range) }\end{array}$ & $\begin{array}{c}17.8 \pm 1.8 \\
18.1(14.1- \\
19.7)\end{array}$ & $\begin{array}{c}13.9 \pm 2.1 \\
14(10.9-17.1)\end{array}$ & $\begin{array}{c}12.5 \pm 1.5 \\
11.7(11.3-14.4)\end{array}$ & $0.000 *$ \\
\hline
\end{tabular}

P- value was calculated by Kruskal Wallis test*Statistically significant.

Table (6): Comparison of Visfatin enzyme levels according to stage of cancer ( $N$. $=60)$ Visfatin level is proportianalycorrelted with stage of cancer

\begin{tabular}{||c||c||c|c||c||c||}
\hline Enzyme & $\begin{array}{c}\text { Stage I } \\
(\mathrm{N}=10)\end{array}$ & $\begin{array}{c}\text { Stage I I } \\
(\mathrm{N}=32)\end{array}$ & $\begin{array}{c}\text { Stage I II } \\
(\mathrm{N}=14)\end{array}$ & $\begin{array}{c}\text { Stage I V } \\
(\mathrm{N}=4)\end{array}$ & P-value \\
\hline \hline Visfatin & & & & & \\
$(\mu \mathrm{g} / \mathrm{dl})$ & $12.4 \pm 1.2$ & $13.7 \pm 1.9$ & $17.6 \pm 1.05$ & $19.4 \pm 0.3$ & \\
Mean \pm S.D. & $12.5(11-$ & $14.1(10.9-$ & $17(16.5-$ & $19.4(19.1-$ & $0.000^{*}$ \\
Median & $14)$ & $17.1)$ & $19.7)$ & $19.7)$ & \\
(Range) & $14)$ & & & \\
\hline
\end{tabular}

P- value was calculated by Kruskal Wallis test

*Statistically significant 
Table (7): Comparison of Visfatin enzyme level among the study groups

\begin{tabular}{|c|c|c|c|c|c|c|c|}
\hline Enzyme & $\begin{array}{l}\begin{array}{l}\text { Malignant } \\
\text { tumor } \\
(\mathrm{N}=60)\end{array} \\
\end{array}$ & $\begin{array}{c}\text { Benign tumor } \\
(\mathrm{N}=\mathbf{1 0})\end{array}$ & $\begin{array}{c}\text { Healthy contro } \\
(\mathrm{N}=15)\end{array}$ & P-value & P1 & $\mathbf{P 2}$ & P3 \\
\hline $\begin{array}{l}\text { Visfatin } \\
(\mu g / d l) \\
\text { Mean } \pm \\
\text { S.D. } \\
\text { Median } \\
\text { (Range) }\end{array}$ & $\begin{array}{c}14.8 \pm 2.7 \\
14.3(10.9- \\
19.7)\end{array}$ & $\begin{array}{c}5.4 \pm 1.8 \\
5.6(1.4-8)\end{array}$ & $\begin{array}{c}2.7 \pm 1.2 \\
2.4(1-5)\end{array}$ & $0.000^{*}$ & $\begin{array}{l}\mathbf{0 . 0 0 0} \\
*\end{array}$ & $\begin{array}{c}0.00 \\
1 *\end{array}$ & $\begin{array}{c}\text { 0.0 } \\
\mathbf{0 0} \\
*\end{array}$ \\
\hline
\end{tabular}

P- value compared the three groups and was calculated byKruskal Wallis test.

P1 compared malignant and benign groups and was calculated by Mann-Whitney test P2 compared benign and healthy control groups and was calculated by Mann-Whitney test

P3 compared malignant and healthy control groups and was calculated by MannWhitney test

*Statistically significant

Table (8): Comparison of Nitric oxide and lipid peroxide and superoxide dismutaseenzyme level among the study groups

\begin{tabular}{|c|c|c|c|c|c|c|c|}
\hline Enzyme & $\begin{array}{l}\text { Malignant } \\
\text { tumor } \\
\quad(\mathrm{N}=60)\end{array}$ & $\begin{array}{l}\text { Benign tumor } \\
(\mathbf{N}=10)\end{array}$ & $\begin{array}{l}\text { Healthy } \\
\text { control } \\
(\mathrm{N}=15) \\
\end{array}$ & P-value & P1 & $\mathbf{P 2}$ & P3 \\
\hline $\begin{array}{l}\text { Nitric } \\
\text { oxide(Mmol/L } \\
\text { ) } \\
\text { Mean } \pm \text { S.D. } \\
\text { Median } \\
\text { (Range) }\end{array}$ & $\begin{array}{c}19.9 \pm 2.9 \\
20.3(15- \\
25)\end{array}$ & $\begin{array}{c}8.9 \pm 1.5 \\
8.4(7.4-12)\end{array}$ & $\begin{array}{c}5.1 \pm 0.6 \\
5(4.1-6)\end{array}$ & $\begin{array}{c}\mathbf{0 . 0 0 0} \\
*\end{array}$ & $0.000 *$ & $\begin{array}{c}\mathbf{0 . 0 0 0} \\
*\end{array}$ & $\begin{array}{c}\mathbf{0 . 0 0} \\
\mathbf{0}^{*}\end{array}$ \\
\hline $\begin{array}{l}\text { lipid } \\
\text { peroxide } \\
(\mu \mathrm{mol} / \mathrm{L}) \\
\text { Mean } \pm \text { S.D. } \\
\text { Median } \\
\text { (Range) } \\
\end{array}$ & $\begin{array}{c}6.3 \pm 1.1 \\
6.2(4-8)\end{array}$ & $\begin{array}{l}3.6 \pm 0.49 \\
3.6(3-4)\end{array}$ & $\begin{array}{c}2.3 \pm 0.52 \\
2(3-4)\end{array}$ & $\begin{array}{c}\mathbf{0 . 0 0 0} \\
*\end{array}$ & $0.000 *$ & $\begin{array}{c}\mathbf{0 . 0 0 1} \\
*\end{array}$ & $\begin{array}{c}\mathbf{0 . 0 0} \\
\mathbf{0}^{*}\end{array}$ \\
\hline $\begin{array}{l}\text { superoxide } \\
\text { dismutase } \\
\text { (Unit/L) } \\
\text { Mean } \pm \text { S.D. } \\
\text { Median } \\
\text { (Range) }\end{array}$ & $\begin{array}{c}241.3 \pm \\
56.3 \\
230.5\end{array}$ & $\begin{array}{c}259 \pm 26.8 \\
245\end{array}$ & $\begin{array}{c}424.5 \pm 24.4 \\
425\end{array}$ & $\begin{array}{c}0.000 \\
*\end{array}$ & $0.000 *$ & $\begin{array}{c}\mathbf{0 . 0 0 1} \\
*\end{array}$ & $\begin{array}{c}\mathbf{0 . 0 0} \\
\mathbf{0}^{*}\end{array}$ \\
\hline
\end{tabular}

P- value compared the three groups and was calculated by Kruskal Wallis test.

P1 compared malignant and benign groups and was calculated by MannWhitney test

P2 compared benign and healthy control groups and was calculated by MannWhitney test

P3 compared malignant and healthy control groups and was calculated by Mann-Whitney test

*Statistically significant 


\section{Discussion}

Colorectal cancer (CRC) is the third most common cancer and the third leading cause of cancer death expected to occur in both men and women in the United States in 2014 ( 1 ) and accounted for almost $10 \%$ of global cancer incidence burden in 2012(2). Despite improvements in screening for early diagnosis, colorectal cancer remains one of the biggest cancer killers in the world and is responsible for over 600,000 deaths each year (3).

There is growing support for the concept that reactive oxygen species (ROS) which are known to be implicated in a range of diseases, may be important progenitors in carcinogenesis (12) .In the last decade, growing number of reports investigating association between ROS and carcinogenesis have been published $(\mathbf{1 2 , 1 3 , 1 4 )}$. However, recent evidence has suggested that the generation of ROS may play important role in all phases of carcinogenesis, that is, the initiation, promotion, and progression stages (12)

Nicotinamide

phosphoribosyltransferase

(NAmPRTase or Nampt) also known as pre-B-cell colony-enhancing factor 1 (PBEF1) or visfatin is an enzyme that in humans is encoded by the PBEF1 gene,this protein has also been reported to be a cytokine (PBEF) that promotes $\mathrm{B}$ cell maturation and inhibits neutrophilapoptosis(5). The three major functions of NAMPT: growth factor, cytokine and nicotinamide

phosphoribosyltransferase(9).Nampt is the rate-limiting enzyme that catalyzes the first step in NAD biosynthesis from nicotinamide by transferring the phosphoribosyl group of 5phosporibosyl- 1-pyrophosphate to nicotinamide (NAM), forming NMN NAD synthesis is completed by NMN adenylyltransferase (Nmnat), which converts NMN into NAD F (15)

In the present study we find thatthe serum levels of visfatin"NAMPT" in patients with benign tumor were significantly higher than in healthy controls, in patients with colorectal cancer the levels is significantly higher than in healthy controls and patients with benign tumor ( $p$-value $<0.001$ ) table(7)in patients with colorectal cancer, patients having advanced stage(III,IV) and whose tumer has high tumor burden and those having metastasing , invasiveness showed significantly higher visfatin levels compared with those with compared groups(I,II) (P-Value <0.05) table(6),(2),(3) respectively .

The present findings are in agreement with previous research studies Nakajima et al (16)which showed thatserum Nampt levels were significantly higher in $115 \mathrm{CC}$ patients than in 115 age-, gender- and body mass index (BMI)-matched controls both in univariate $(\mathrm{p}<0.01)$ and multivariable analyses (OR: 2.95, 95\% C.I. 1.862-4.787, $\mathrm{p}<0.01)$ In addition Nakajima et al., (16) reported that serum Nampt levels may represent a promising biomarker of CC malignant potential and stage progression. Circulating Nampt gradually increased with tumor stage progression $(\mathrm{p}<0.01)$ (16).Nampt was first reported to be overexpressed in colorectal cancer using suppression subtractive hybridizationHufton et al;(10).

Additionally plasma Nampt levels in patients with advanced and early cancer were higher than in controls(11) . Xiaoqun et al;(17) reported that Nampt expression was significantly higher in human colorectal adenoma $(P<0.05)$ and carcinoma $(P<0.001)$, furthermore the 
positive rate of Nampt expression in the malignant colorectal adenocarcinoma was higher than in the benign colorectal adenoma $(P<0.001)$. In contrast to our study, Xiaoqun et al;(17) found that there is no correlation of Nampt expression with clinic-pathological features of CRC patients, such as gender, age, location, tumor size, clinical stages, depth of wall invasion, and lymph node metastasis.

In the present study we find that the levels of Nitric oxide, in patients with benign tumor were significantly higher than in healthy controls ,in patients with colorectal cancer the levels is significantly higher than in healthy controls and patients with benign tumor ( $p$-value $<0.001)$ table( 8), also in patients with colorectal cancer, patients having advancing stage(III,IV) showed significantly higher Nitric oxide levels compared with those with early stag(I,II) (PValue $<0.05)$.Also the levels of Nitric oxide in cancer patients is higher in cases with metastasis than those with regional disease(no metastasis) (pvalue 0.000 ).

The present findings are in agreement with EL-Deek et al;(18), who reported that the levels of Nitric oxide ,in patients with benign colorectal tumor were significantly higher than in healthy controls, in patients with colorectal cancer the levels is significantly higher than in healthy controls and patients with benign tumor (p-value< 0.001), also in patients with colorectal cancer, having advancing stage(III,IV) showed significantly higher Nitric oxide levels compared with those with early stag(I,II) (P-Value <0.05) .Also the levels of Nitric oxide in cancer patients is higher in cases with metastasis than those with regional disease(no metastasis, also in agreement with previous studies which showed that,
NO activity and NO synthesis were high in colorectal tumors tissue and in plasma .

In the present study we find that the levels of lipid peroxide (MDA) ,in patients with benign tumor were significantly higher than in healthy controls, in patients with colorectal cancer the levels is significantly higher than in healthy controls and patients with benign tumor ( $p$-value $<0.05)$ table(8).

Also we found that the levels of superoxide dismutase (SOD) in patients with benign tumor were significantly lower than in healthy controls, in patients with colorectal cancer the levels is significantly lower than in healthy controls and patients with benign tumor table(8) .

The present findings are in agreement with Haklar et al;(19)whofound that the human colorectal tumors (adenomas and carcinomas) have increased levels of different markers of oxidative stress, such as increased levels of ROS (measured by chemiluminescence), nitric oxide (NO) - also In the last decade, growing number of reports investigating association between ROS and carcinogenesis have been published $(12,13,14)$.Observations similar to our findings have been reported in studies on colorectal cancer(17).

In conclusion, our study relieved that there is positive relation between level of visfatin and colorectal canceroccurrence and cancer clinicopathological criteria as proven ,reported by (16).Also our study relieved that the levels of oxidant markers as(NO and lipid peroxidation productes as "MDA") were highly elevated in colorectal cancer group, benign lesions group comparing to healthy control group., in contrast the levels of antioxidant enzyme (superoxide dismutase) where altered "decreased "in colorectal cancer group 
, benign lesions group comparing to healthy control group as proven ,reported by (15).

\section{Referances}

1. Siegel R, Ma J, Zou Z, Jemal A(2014): Cancer statistics, CA Cancer J Clin.64:9-29.

2. Bosman FT, Hamilton SR, Lambert $R$ (2014): Colorectal cancer. In: Stewart BW, Wild CP. World Cancer Report 2014, International Agency for Research on Cancer; pp. 558-75.

3. Edwards BK et al(2006): Annual Report to the Nation on the Status of Cancer, 1975-2006, Featuring Colorectal Cancer Trends and Impact of Interventions (Risk Factors, Screening, and Treatment) to Reduce Future Rates. Cancer (2009) 116(3):544-573.

4. Koyanagi K, Bilchik AJ, Saha S, Turner RR, Wiese D, McCarter M. et al (2008): Prognostic relevance of occult nodal micrometastases and circulating tumor cells in colorectal cancer in a prospective multicenter trial. Clin Cancer Res.; 14:7391-6.

5. Samal B, Sun Y, Stearns G, Xie C, Suggs $S$ and McNiece I (1994): Cloning and characterization of the cDNA encoding a novel human pre-Bcell colony-enhancing factor. Mol Cell Biol Feb;14(2):1431-7.

6. Fukuhara A, Matsuda M, Nishizawa M, Segawa K, Tanaka M, Kishimoto K, Matsuki Y, Murakami M, Ichisaka T, et al; (2005):"Visfatin: a protein secreted by visceral fat that mimics the effects of insulin". Science. 307 (5708)426-30.

7. Imai. S.I (2009): "Nicotinamide phosphoribosyltransferase (Nampt): a link between NAD biology, metabolism, and diseases," Current Pharmaceutical Design, vol. 15, no. 1, pp. 20-28.

8. Galli M, Van Gool F, Rongvaux A, Andris $F$ and Leo $O$ (2009): The nicotinamide phosphoribosyltransferase: a molecular link between metabolism, inflammation, and cancer.Cancer Res. 2010 Jan 1;70(1):8-11. Epub 2009 Dec 22.

9. Zhang LQ, Heruth DP and Ye SQ(2011): Nicotinamide Phosphoribosyltransferase in Human Diseases Bioanal Biomed Jan 7; 3:1325.

10.Hufton SE, Moerkerk PT, Brandwijk R, de Bruine AP, Arends JW, Hoogenboom HR (1999): A profile of differentially expressed genes in primary colorectal cancer using suppression subtractive hybridization.FEBSLettDec 10;463(12):77-82.

11. Chen M, Wang Y, Li Y, Zhao L, Ye S, Wang S(2013) : Association of plasma visfatin with risk of colorectal cancer: An observational study of Chinese patients. Asia-Pacific journal of clinical oncology .

12.Valko.M, D. Leibfritz, J. Moncol, M. T. D. Cronin, M. Mazur, and J. Telser (2007): "Free radicals and antioxidants in normal physiological functions and human disease," International Journal of Biochemistry and Cell Biology, vol. 39, no. 1, pp. 44-84.

13.Cejas. P, E. Casado, C. Belda-Iniesta et al (2004) :"Implications of oxidative stress and cell membrane lipid peroxidation in human cancer (Spain)," Cancer Causes and Control, vol. 15, no. 7, pp. 707-719.

14. Mena. S, A. Ortega, and J. M. Estrela (2009): "Oxidative stress in environmental-induced carcinogenesis," Mutation Research, vol. 674, no. 1-2, pp. 36-44.

15. UpadhyaSharmila, SubramanyaUpadhya, S. Krishna Mohan, K. Vanajakshamma,MamathaKunder, Seema Mathias(2004): OXIDANTANTIOXIDANT STATUS IN COLORECTAL CANCER 
PATIENTSBEFORE AND AFTER TREATMENT indian Journal of Clinical Biochemistry, , 19 (2) 80-83.

16. Nakajima TE, Yamada Y, Hamano T, Furuta K, Matsuda T, Fujita S, Kato K, Hamaguchi T, Shimada Y (2010):Adipocytokines as new promising markers of colorectal tumors: adiponectin for colorectal adenoma, and resistin and visfatin for colorectal cancer.Cancer Sci.;101(5):1286-91. Epub 2010 Jan 31.

17. XiaoqunLv,Lingyun Zhang, Yanyan Zhu,Harun M. Said,Jimin Shi, and Guoxiong $\quad X u(2015)$ : Regulative Effect of Nampt on Tumor Progression and Cell Viability in
Human Colorectal Cancer; 6(9): 849858.

18. El-Deek.S.EM ,Naglaa $K$ Idriss ,Randas Hana , Madleen AA Abdou , Doaa W Maksemose , Madeha M zakhary (2013): The Role of Angiogenic Biomarkers in Gastrointestinal CancerIbnosina J Med BS 2013,5(4):196-205

19. Haklar. G, Sayin-Özveri. E, Yüksel .M, Ö. Aktan. A, and YalçinA. S (2001): "Different kinds of reactive oxygen and nitrogen species were detected in colon and breast tumors," Cancer Letters, vol. 165, no. 2, pp. 219-224. 
